\title{
Gross Output: A New Revolutionary Way to Confuse Students about Measuring the Economy
}

\author{
David Colander \\ Middlebury College, Middlebury, Vermont 05753, USA.
}

Eastern Economic Journal (2014) 40, 451-455. doi:10.1057/eej.2014.39

The Bureau of Economic Analysis (BEA) recently started providing quarterly figures on a new measure of the aggregate economy that they call gross output. Supply-side economists consider it a major new development. For example, in Forbes Magazine, Steve Forbes describes it as a "New, Revolutionary Way to Measure the Economy" and states "Believe Me, This Is A Big Deal" [Forbes, 2014]. He writes that the gross output measure will have "a profound and manifestly positive impact on economic policy and politics."

While the new measure is hardly revolutionary, and is unlikely to make a profound impact, I think adding it is a good idea. However, I suspect the reasons why I think it is a good idea are quite different than the reasons Steve Forbes thinks it is. I suspect he likes it because it has what he sees as a "business/supply" rather than the "consumer/demand" focus that many supply siders consider the current output measures to have. I like the new measure for two quite different reasons. The first is that it may be useful in forecasting, and the second is that by totally confusing people about what is meant by gross output, it may further the movement away from our fixation on aggregate output measures as a measure of welfare for the aggregate economy.

\section{HISTORY OF THE GROSS OUTPUT MEASURE}

Before I explain my reasoning, let me briefly discuss the history of the new gross output measure. The impetus to provide this new measure came from Mark Skousen, a maverick supply-side economist who has been pushing for such a measure for the last 25 years, at least. He made the argument for the measure in "The Structure of Production" [Skousen, 1990, 2007]. In it he argued that gross output was a much better measure of production in the economy than the standard Gross National Product (GNP) and Gross Domestic Product (GDP) measures.

Even before Mark had published the book he had written me about the measure. He felt that since we were both harsh critics of the AS/AD framework, I would be supportive of his new measure. I wrote him back that I saw the measure as different, but not better; which measure was better depended on what one was trying to measure. I saw the two measures as compliments, not substitutes.

That, I suspect, was the standard economist's response. At least it should have been; despite being a maverick in my own right, I'm more standard than Mark. In any case, 
initially, Mark didn't have much luck in pushing for his measure, and his "gross output" measure never really was discussed in the economic literature. But Mark is a persistent well-connected supply-side economist, and he kept at it. So I wasn't all that surprised when last year Mark wrote me that the BEA decided to start providing the measure quarterly. (It has always been available on a yearly basis. I'm not sure what the politics of that BEA decision were, but I suspect they were interesting.)

\section{A REFRESHER ON AGGREGATE INCOME ACCOUNTING}

To understand what is at issue with the new measure, it is helpful to review a little aggregate income accounting. This is useful because, unless you teach a principles of macro course, or are a business economist involved in forecasting, I suspect that you have not considered aggregate income accounting issues since your undergraduate macro course in college, if then. (I say "if then" because recently aggregate accounting topics have been getting less and less focus in the principles texts.)

Aggregate income accounting is the framework macroeconomists use to think about the aggregate economy and to relate their models to the real world. It is a big deal because it frames our discussion of the macro economy. Aggregate income accounting is based on an intricate set of carefully defined tautological accounting relationships that follow from the definitions of concepts such as income, output, consumption, investment, and government spending.

Introductory macro classes used to grill undergraduate economic students on these definitions and accounting tautologies. That grilling included an explanation of why economists didn't use other measures such as the one that Skousen prefers. Unfortunately, far less grilling is going on in undergraduate programs today. In graduate programs, students are too busy learning dynamic optimization techniques, and other esoteric topics, to spend time on the history and precise definitions of these aggregate accounting concepts. So what national income accounting expertise still exists now resides with some older economists, economists at the BEA, and business economists who have to make actual forecasts and use the numbers to explain to others what is happening in the real world economy.

\section{THE DIFFERENCE BETWEEN GDP AND GROSS OUTPUT}

A fundamental concept around which aggregate income accounting is based is GDP. It is defined as the aggregate economic output of the economy, and is meant to measure the total amount of goods and services available for government and consumers to consume. (For ease of exposition, I will leave out any discussion of the international sector.)

To understand what is meant by GDP, let's consider each term separately. Let's start with the term "domestic." The adjective "domestic" replaced the previous adjective "national" in the 1970s. Before that time we talked about Gross National Product, not Gross Domestic Product. The difference between the two is usually small, but it makes a good question for grilling students. GDP is a measure of gross final domestic output, where "domestic" means output physically produced in the United States, and "national" means output produced by US national firms and citizens. The domestic production measure is used by most countries around the world and is easier to measure than the national production since, with globalization, it is hard to tell what is a US firm and what is a foreign firm. So "domestic" is simply a descriptor of some technical issues about measuring aggregate output. 
Let's next consider the term "gross." In aggregate income accounting, the term "gross" has a specific meaning. It means that the measure includes production that is used for investment, and thus will not be available for consumption by government or consumers. After one subtracts that investment, one has net domestic product (NDP) and it is NDP that represents the output available for private and government consumption. Net production is gross production minus investment. The reason economists don't focus on NDP, and instead focus on GDP is that we don't have good measures of investment. To arrive at NDP we generally simply subtract a set percentage - what is called a capital consumption allowance. Given that fact, we often use the GDP measure as a proxy for final output of the economy.

Finally, let's consider the meaning of the third term "product." "Product" in aggregate income accounting is just another term for output. One could have as well called it gross domestic output. Skousen [2014], in his Wall Street Journal valedictory op-ed article calls his concept of gross output a "better economic measure" than GDP because it is a supplyside statistic that measures the production side of the economy, whereas the current measure of output, GDP, measure the demand side of the economy. That characterization doesn't fit with the aggregate accounting conventions; GDP is a measure of the productive side of the economy just as much as gross output is.

When we put all these terms together we see that GDP is essentially a measure of gross output, and always has been. This presents a terminological problem with the new gross output measure. By calling the new measure Gross Output the BEA has created two equivalent names for two quite different concepts. That can only confuse. (I am already thinking how I will handle the confusion in my next edition of the text.) So what I am saying is that the new gross output measure should never have been called gross output. The name is already taken.

\section{WHAT SHOULD THE NEW MEASURE HAVE BEEN CALLED?}

To see what the new measure should have been called, let's consider how the two gross output measures differ. They are based on different concepts of "gross." The new Gross Output measure includes intermediate sales from one firm to another; GDP doesn't. The new measure has little meaning in aggregate accounting because it double counts in aggregate income accounting terms. Thinking in an aggregate accounting frame, the new concept would more appropriately have been called gross domestic market activity, (GDMA) because that's the information that it provides. It is a measure of market activity - how much activity is taking place in the market. It has little to do with output available for consumption by government and consumers, and thus is not comparable to the GDP measure.

Expressed another way, the difference between the two is that GDP nets out value-added production, where value added is interfirm sales. This means that if a firm outsources some of its production - say it divests one of its accounting divisions, but hires the divested company back to keep doing its accounting there will be an increase in gross output, but no increase in the GDP measure since there is no change in employment or production - it is just that now an activity that was internal to the firm becomes a market activity.

\section{WHY THE CONFUSION MAY BE USEFUL}

Despite my objections to the name, and the confusion that it will cause, I still support the publication of the new measure. For forecasting, the new measure may be more helpful 
than the GDP measure, because it provides information of goods in process. But the main reason I support the new measure is for the confusion it will cause. That confusion is good because of the misuse and misinterpretation of the GDP measure.

What I mean by this is that although GDP purports to measure final output, it does so only in a very rough sense. Moreover, even if it did actually measure final output, final output is a poor measure of societal welfare, which GDP is often used for. As a proxy for social welfare, GDP places way too much emphasis on economic and market measures of welfare and not enough on psychological, sociological, and cultural non-market measures of welfare. Social welfare is much too complicated to be captured by GDP. If we were really interested in social welfare, we would be exploring the development of an alternative measure such as Sen's [1993] capabilities approach that includes measures related to health, education, longevity, and morbidity, among others. In an affluent society such as ours, changes in aggregate GDP are poor measures of changes in societal welfare. By adding another measure of gross output, that lack of a close connection between changes in GDP and changes in social welfare will likely be emphasized, and possibly reexamined.

\section{ARBITRARY DEFINITIONS}

Even considered only as a measure of aggregate economic output, GDP is problematic because, of necessity, it includes many arbitrary, politically charged and ideological assumptions and conventions that undermine its usefulness. For example, housing services are estimated and included in GDP, but in-home work is not. Similarly, government spending on goods and services is included as a final good at cost, not as an intermediate good.

Early on, when they were creating the aggregate income accounts, there was a debate about whether government spending on goods and services should be considered an intermediate good or a final good. Possibly, in part because of a desire of some of those designing the measure to make it politically easier to increase government spending, the decision was made to include government spending on goods and services as a final output at cost, not as an intermediate good. This decision meant that increases in government spending on goods and services increases GDP directly, whereas had the other decision been made, increases in government spending would not have increased GDP; instead they would have lowered productivity.

To design an accounting measure choices had to be made. If the GDP measure was used as the rough gauge for the economic component of social welfare that it was meant to be, it would have been fine. But when that rough gauge becomes a carefully watched statistic, and tenths of a percentage point differences are represented as implying something important has happened, as is currently the case, then the measure is being misused. To the degree that the new gross output measure undermines the misuse of GDP figures, it is something to be applauded.

\section{CONCLUSION}

So what is one to conclude from all this? My first conclusion is that accounting measures are simply accounting measures. It is necessary to have a deep knowledge of the accounting system they are based on to understand the information the accounting measures are actually conveying. My second conclusion is that many quite different accounting measures are not better or worse; they are simply different. Problems arise when an accounting measure is used as a proxy for something it is not a good proxy for. 
If one is interested in market activity, as some forecasters and business economists may well be, then GDMA is a better measure than GDP because GDP was not designed to measure market activity. But if one is interested in output available for consumption and government measure, GDP is a better measure. If one is interested in social welfare, both are lousy measures. The general use of changes in GDP as a measure for changes in social welfare is a major problem. Thus, some more confusion about it, as the gross output measure will bring about, can be seen as a useful development.

\section{References}

Forbes, Steve. 2014. New, Revolutionary Way to Measure the Economy is Coming — Believe Me, This is a Big Deal. Forbes Magazine (April 14).

Sen, Amartya. 1993. Capability and Well-Being, in The Quality of Life, edited by M. Nussbaum, and A. Sen. Oxford: Clarendon Press, 30-53.

Skousen, Mark. 1990, 2007. The Structure of Production. New York: New York University Press.

Skousen, Mark. 2014. At Last, a Better Economic Measure: Gross output will Correct The Fallacy Fostered by GDP that Consumer Spending Drives the Economy. Wall Street Journal (April 22). 